\title{
Applications of High-Resolution EELS Near-Edge Structures in Complex Oxides
}

\author{
G. Radtke*, C. Maunders*, S. Lazar**, A.D. Lozano-Gorrin*, J.E. Greedan*, G. A. Botton**** \\ *Brockhouse Institute for Materials Research, McMaster University, 1280 Main St. West, Hamilton, \\ L8S 4M1, Canada \\ ** National Centre for High Resolution Electron Microscopy, Kavli Institute for Nanoscience, Delft \\ University of Technology, Lorentzweg 1, 2628CJ Delft, The Netherlands.
}

Electron energy loss near edge structures obtained with high energy resolution can provide a wealth of information on fine features previously not detectable with conventional resolution energy loss spectroscopy [1-3]. These fine features can provide key information on structure and bonding in materials including information on valency, and spin state and coordination of transition metal atoms with high spatial resolution. When the technique is applied to complex crystalline structures, it is possible to probe effects of substitutions in the lattice and their influence on the electronic structure of materials. In our recent work we have therefore attempted to probe the systematic trends in a few series of compounds potentially attractive for their functional properties and their structure in order to provide useful information on their properties.

Experiments were carried out on a FEI Tecnai-200 FEG equipped with a monochromator yielding a resolution of about $0.1 \mathrm{eV}$ measured at the full width at half maximum of the zero-loss peak. Recent experiments have further demonstrated the effect of numerical deconvolution on low energy loss spectra obtained with a monochromator [4] these being particularly useful for the enhancement of features down to $0.5 \mathrm{eV}$ losses. A variety of samples in the perovskite based series $\mathrm{Sr}_{2} \mathrm{Ru}_{2-\mathrm{x}} \mathrm{Co}_{\mathrm{x}} \mathrm{O}_{6-\delta}$, the ilmenite series $\mathrm{MTiO}_{3}$ where $\mathrm{M}$ is $\mathrm{Mn}, \mathrm{Co}, \mathrm{Fe}$ or $\mathrm{Ni}$, as well as spinels in the $\mathrm{MnCu}_{2} \mathrm{O}_{4}$ series were studied in this work. Transmission electron microscopy samples were prepared by crushing powders and dispersing them on $\mathrm{C}$ coated $\mathrm{Cu}$ grids. Spectra were obtained with an energy resolution of $0.1-0.2 \mathrm{eV}$ throughout this work. Calculations of energy loss spectra to support our interpretation of structure and valency were carried out using the atomic multiplet technique described elsewhere [5].

As examples of the work, we show here spectra of the $\mathrm{Mn}_{2-3}$ and $\mathrm{Co} \mathrm{L}_{2-3}$ edges in the ordered corundum (ilmenite) structure $\mathrm{MnTiO}_{3}$ and $\mathrm{CoTiO}_{3}$ respectively where multiplet calculations indicate unambiguously the presence of high-spin $\mathrm{Mn}^{2+}$ and $\mathrm{Co}^{2+}$ in the octahedral sites (figure 1a, b) and the clear benefits of enhanced energy resolution of the spectra. In the series of ilmenite-based compounds, studies of the $\mathrm{O}$ K edges show the similarities of the spectra with $\mathrm{TiO}_{2}$ polytypes structures thus indicating the strong and dominant hybridization of the Ti-3d band with the O-2p orbitals (Fig. 2) and the intrinsically broad near-threshold features [6]. The effect of the enhanced resolution is also demonstrated in the $\mathrm{Co} \mathrm{L}_{2-3}$ edges in the series of $\mathrm{Sr}_{2} \mathrm{Ru}_{2-\mathrm{x}} \mathrm{Co}_{\mathrm{x}} \mathrm{O}_{6-\delta}$ compounds where it is possible to deduce, with atomic multiplet calculations, that the Co atoms are in a highspin configuration and $3+$ oxidation state (figure 3$)$. With increasing Co content in the series $(x=0.5$, 1.0 and 1.5), the spectra show no significant changes in either the oxidation or spin state suggesting that the structural distortions detected by X-ray work, as the composition is altered, do not result in significant changes in the magnetic structure of Co. These results clarify some trends in magnetic measurements [7]. Further work on compounds based on spinel structure and oxides with highly correlated electrons will be presented [8]. 


\section{References}

[1] M. Terauchi, M. Tanaka, K. Tsuno, M. Ishida, J. Microsc. 194 (1999) 203.

[2] C. Mitterbauer, et al., Ultramicroscopy 96 (3-4) (2003) 469.

[3] S. Lazar, G.A. Botton, M.-Y. Wu, F.D. Tichelaar, H.W. Zandbergen Ultramicroscopy 96, (2003) 535.

[4] S. Lazar, G.A. Botton, H.W. Zandbergen, Ultramicroscopy, accepted.

[5] F.M.F. de Groot, Coordination Chemistry Reviews 249 (2005) 31.

[6] G. Radtke, S. Lazar and G.A. Botton, Submitted.

[7] A.D. Losano-Gorrin et al., In preparation.

[8] This work is supported by NSERC. We are grateful to the Dutch Government NWO and Prof. H.W. Zandbergen for access to the EELS system in Delft and for funding a visiting professorship in Delft. A.D. Lozano-Gorrin is very grateful to Dr. J.E. Greedan for his very important cooperation on the preparation of the perovskites $\mathrm{Sr}_{2} \mathrm{Ru}_{2-\mathrm{x}} \mathrm{Co}_{\mathrm{x}} \mathrm{O}_{6-\delta}$.

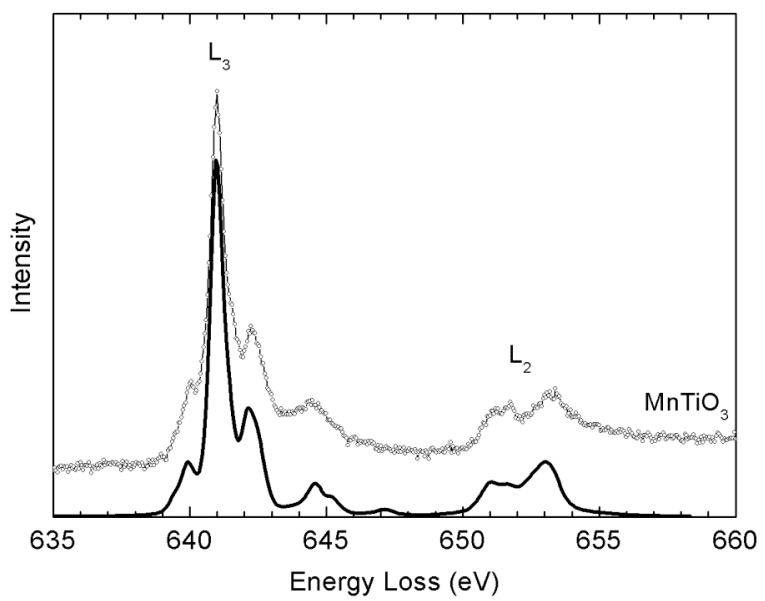

Figure 1a) $\mathrm{Mn} \mathrm{L}_{2-3}$ edge in $\mathrm{MnTiO}_{3}$; full line multiplet calculations for $\mathrm{Mn}^{2+}$.

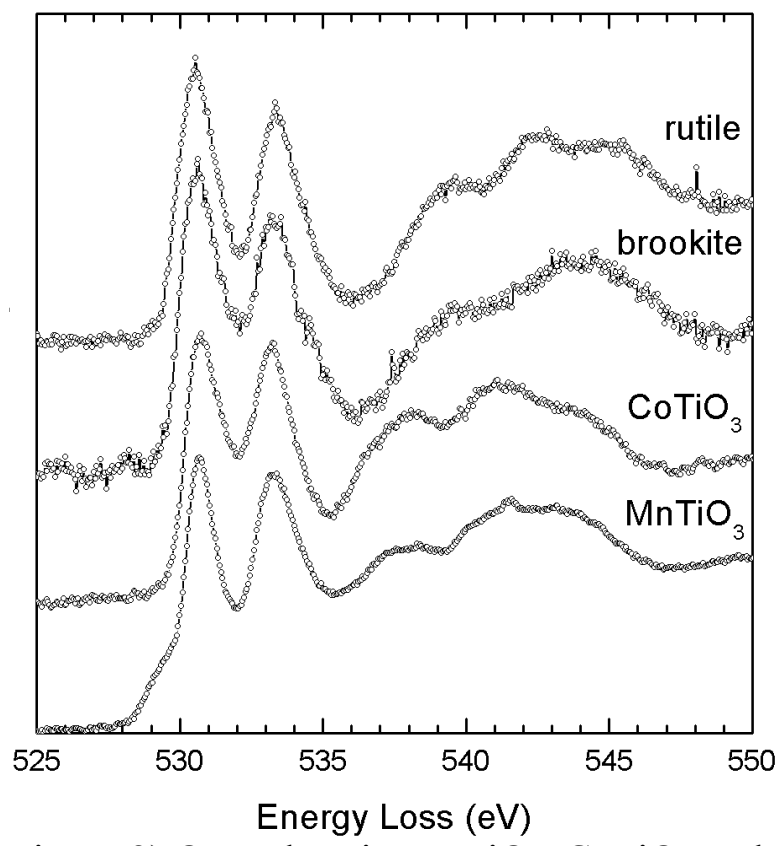

Figure 2) $\mathrm{O} \mathrm{K}$ edges in $\mathrm{MnTiO}_{3}, \mathrm{CoTiO}_{3}$ and $\mathrm{TiO}_{2}$ (brookite and rutile).

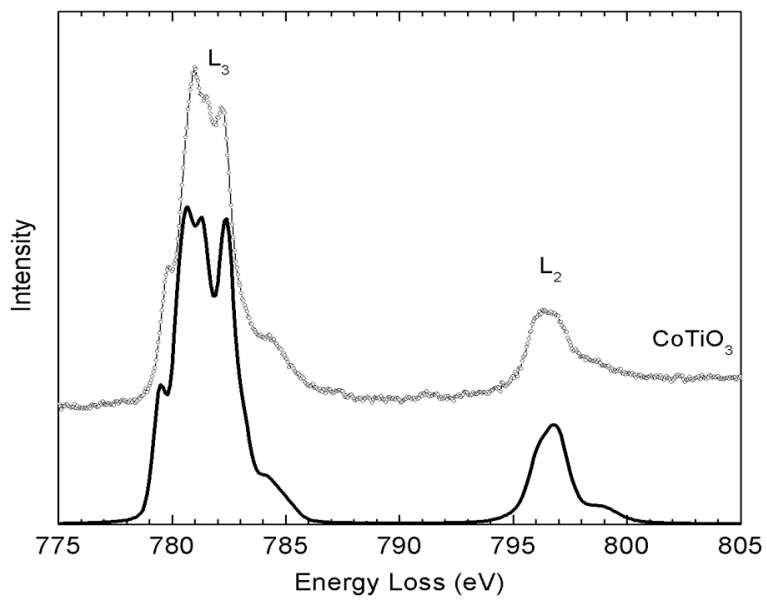

Figure 1b) $\mathrm{Co}_{2-3}$ edge in $\mathrm{CoTiO}_{3}$ full line multiplet calculations for $\mathrm{Co}^{2+}$.

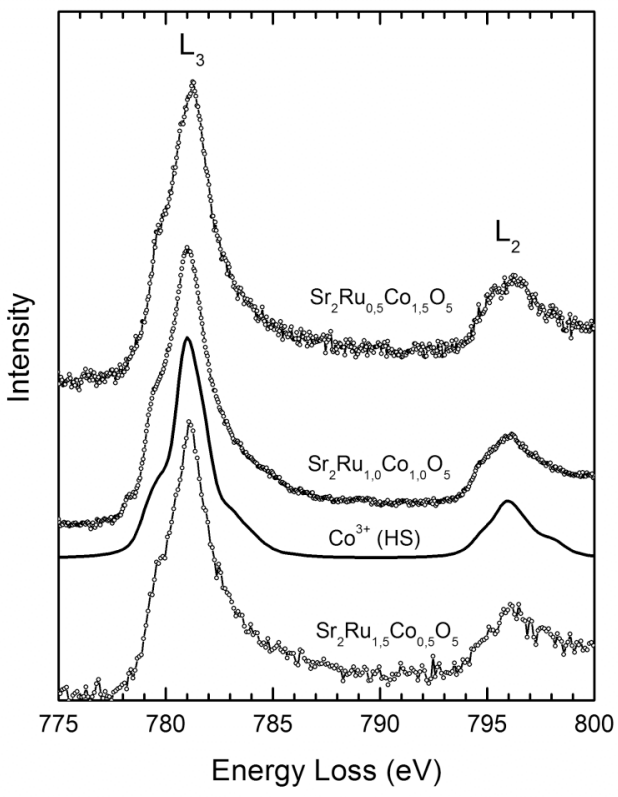

Figure 3) $\mathrm{Co} \mathrm{L} \mathrm{L}_{2-3}$ edges in $\mathrm{Sr}_{2} \mathrm{Ru}_{2-\mathrm{x}} \mathrm{Co}_{\mathrm{x}} \mathrm{O}_{6-\delta}$, full line: multiplets for $\mathrm{Co}^{3+}$ high-spin state. 